\title{
¿Huelgas antes de los sindicatos? Notas para una historia larga de las luchas de los trabajadores en Argentina y Uruguay
}

\author{
Gabriel Di Meglio, Raúl Fradkin y Florencia Thul
}

Ravignani, UBA Conicet, Unsam / Ravignani, UBA Conicet, UNLu / FHCE, Udelar, SNI
gabrieldimeglio@gmail.com / raul.fradkin@gmail.com / florenciathul@gmail.com

Title: Strikes before the unions? Notes for a long history of the struggles of workers in Argentina and Uruguay

Resumen: La consolidación de una sociedad capitalista a fines del siglo XIX y la llegada de inmigrantes europeos con militancia de izquierda se presentan habitualmente como los factores clave para comprender el origen del movimiento obrero argentino y uruguayo, en los que las primeras huelgas se habrian iniciado a partir de 1878. Todo esto tiene una importancia indudable, pero encuadra esta historia en el "tiempo corto". ¿Alcanza con él para explicar las prácticas del movimiento obrero emergente? Este artículo plantea la conveniencia de rastrear las formas de protesta y resistencia de los trabajadores en el largo plazo, considerando la interacción entre coacción, mercado y acciones colectivas, las huelgas anteriores a 1878, las disputas laborales en el ámbito militar, y otras formas de conflicto.

Palabras clave: clase trabajadora - movimiento obrero - huelga - sublevación - salario

Summary: The consolidation of a capitalist society at the end of the 19th century and the arrival of European immigrants with left-wing militancy are usually presented as the key factors to understand the origin of the Argentine and Uruguayan labor movements, in which the first strikes would have started after 1878 . All this is undoubtedly important, but frames this story in the "short time". Is it enough to explain the practices of the emerging workers' movement? This article raises the convenience of tracking the forms of protest and resistance in the long term, considering the interaction between coercion, market and collective actions, the strikes prior to 1878 , labor disputes in the military field, and other forms of conflict.

Key Words: working class - workers' movement - strike - uprising - wage

Recepción: 17 de diciembre de 2018. Aprobación: 1 de febrero de 2019 .

(Archivos, año VII, no 14 , marzo de 2019, pp. 11-31) 


\section{Introducción}

El 14 de enero de 1826, el oficial a cargo de las baterías en Punta Gorda, Entre Ríos, comunicó que los soldados se negaban a trabajar porque no les habian pagado su sueldo. Pidió que se los abonaran con urgencia, ya que existía un "estado de sublevación". Y efectivamente un mes más tarde se rebelaron y huyeron al interior de la provincia (notas de José Luis Domínguez, AGN Argentina, X, 4-4-6). El episodio ocurrió entre las tropas movilizadas para la guerra entre las Provincias Unidas del Río de la Plata y el imperio del Brasil, y puede perfectamente ser estudiado en una investigación sobre ese conflicto, en una de historia militar o en un estudio de las acciones populares de la época.

Ahora bien, también puede ser pensado como un conflicto laboral, protagonizado por trabajadores -algunos voluntarios, otros forzadosque dejaron sus tareas, descontentos por el atraso de sus salarios. E1 pequeño evento, que por su naturaleza y su forma de acción empezó como una "huelga", no tiene nada de excepcional. Por el contrario, hubo muchos similares en los ejércitos y las milicias de la región en los siglos XVIII y XIX. Y también, fuera de las fuerzas militares, se produjeron diversas negativas colectivas a trabajar y otros reclamos laborales en distintos establecimientos productivos, mucho antes de que los trabajadores comenzaran a constituir sus primeras organizaciones. Algunos de estos episodios fueron investigados por quienes se han dedicado a la historia agraria, y también a la historia laboral del periodo anterior al último cuarto del siglo XIX.

Sin embargo, casi no han sido explorados por la historiografia de la formación de la clase trabajadora en el espacio rioplatense, y en particular del movimiento obrero, cuyos "más remotos orígenes" suelen vincularse con los inmigrantes europeos llegados a mediados del siglo XIX a las ciudades del Litoral, y con la aparición de "organizaciones de expresión autónoma” de los trabajadores (Falcón, 1984: 13). Hay un consenso mayoritario en que la Sociedad Tipográfica Bonaerense fundada en 1857 fue la primera mutual protosindical argentina, mientras que en 1865 se creó una similar en Montevideo. A su vez, se ha supuesto que la huelga de los tipógrafos en 1878 fue la primera en Argentina, al tiempo que las huelgas de la década de 1880 fueron señaladas como las primeras de Uruguay (Marotta, 1960; Falcón, 1984; Zubillaga y Balbis, 1985). El foco se ha puesto en la asociación entre el movimiento obrero y las posiciones de izquierda, por lo cual aspectos como la llegada de emigrados de la Comuna de París o la primera circulación de las ideas de Marx sobre todo entre grupos inmigrantes han sido bien investigadas (Tarcus, 2007). Sin embargo, también conviene recuperar que la mayor parte de los socios de la Sociedad Tipográfica en 1879 habían nacido en 
Argentina y medio centenar en los países vecinos; a ellos, Roberto Payró los calificó como "la clase más independiente y levantisca de nuestra Capital" (Ratzer, 1969: 25). ${ }^{1}$

El hecho de que muchos contemporáneos destacaran a finales del siglo la novedad de los conflictos protagonizados por trabajadores reforzó la noción de que su historia era corta. Por ejemplo, un folleto publicado en Buenos Aires en 1896 proclamaba que "las huelgas entre nosotros son de un período reciente; el pasado no las habia conocido" (Poy, 2014: XXIII). Es indudable que el masivo arribo de inmigrantes, la importancia de anarquistas, socialistas y sindicalistas revolucionarios, y los cambios económicos y urbanos provocados por el auge comercial de fin de siglo son elementos decisivos para entender la aparición del movimiento obrero. No obstante, esas grandes transformaciones han sido a veces retratadas como un recomienzo absoluto en el que solo lo nuevo parece ser digno de analizarse, en desmedro de rasgos y experiencias más antiguas.

Hubo autores que iniciaron sus análisis de la formación de la clase obrera con algunas referencias al temprano siglo XIX (Mafud, 1988) o que trazaron vínculos entre las acciones de los gauchos y los obreros (Viñas, 1971), pero la cuestión no ha sido indagada sistemáticamente. Como advirtió Nicolás Iñigo Carrera, antes del periodo que habitualmente se toma para investigar las luchas de los trabajadores hubo "infinidad de huelgas", que denomina espontáneas, las cuales "no dieron lugar a una organización obrera más o menos perdurable y que constituyen la prehistoria del movimiento obrero" (2011: 47). Algunas investigaciones han empezado a avanzar en ese sentido, llevando más atrás los orígenes de la conflictividad obrera (Román, 2004; Leyes, 2014; Thul, 2016). En otros países de la región esto se viene haciendo desde antes. Por ejemplo, en Colombia y Chile se han buscado las conexiones entre movimientos populares decimonónicos, en particular del artesanado, y la clase obrera del siglo XX (Sowell, 2006; Grez Toso, 2007). En Brasil, posiciones parecidas a las de sus vecinos australes cambiaron cuando las luchas laborales de los esclavos fueron incorporadas a la historia de los trabajadores (Chalhoub y Teixeira da Silva, 2009).

El objetivo de este artículo es rastrear las evidencias disponibles e indagar si las disputas laborales de los siglos XVIII y XIX producidas en el litoral rioplatense pueden haber jugado un papel en el proceso de formación de la clase obrera en Argentina y en Uruguay. La decisión de observar estos países al mismo tiempo tiene que ver con que en ambos se constata la misma situación historiográfica respecto de este tema,

1. Por razones de espacio no podemos consignar la abundante bibliografia que existe en ambos países sobre el temprano movimiento obrero. 
pero sobre todo con que la clase obrera consolidada a fines del siglo XIX en algunas ciudades tenía relaciones muy fluidas entre sí. Desde el siglo XVIII, los trabajadores, "criollos" e inmigrantes, libres o esclavos, circulaban entre los puertos y las áreas rurales rioplatenses, y por lo tanto la suya es una historia que necesita atender a esa circulación y a sus experiencias en común para hacerse inteligible. Por ejemplo, la huelga general de 1902 fue empujada por la Federación de Estibadores de los Puertos de la República Argentina y del Uruguay que se constituyó en abril de ese año, y se extendió a muy diferentes gremios de diversas ciudades (Boido, 2002).

El trabajo es un ensayo exploratorio basado en nuestras propias investigaciones y en las de otros colegas. No es una critica historiográfica ni una investigación en regla, sino una búsqueda en la bibliografia y en algunas fuentes de elementos que permitan identificar algunos nudos problemáticos. Más que pensar hacia adelante, rastreando los orígenes de un actor del siglo XX, nos interesa pensar la formación de la clase obrera como producto de un proceso largo y sinuoso de antagonismos y experiencias. Y el foco está puesto en el litoral porque allí se concentran los estudios posteriores sobre el movimiento obrero, aun sabiendo que es fundamental tener en cuenta lo ocurrido en otras regiones y, en especial, en el antiguo Tucumán.

Primero nos ocupamos de la cuestión de la coacción, el mercado y las acciones colectivas de los trabajadores, luego de las huelgas anteriores a 1878 , en tercer lugar, de las disputas laborales encuadradas en el ámbito militar, y finalmente de otras formas de organización y conflicto.

\section{Coacción, mercado y acción colectiva}

Aproximarse a las experiencias de los trabajadores durante los siglos XVIII y XIX implica tener en cuenta algunos aspectos. En primer lugar, la extrema heterogeneidad de esos trabajadores, por sus diferentes orígenes raciales y regionales, y su permanente renovación a partir de las intensas migraciones que atravesaron el área rioplatense. En segundo término, sus diferentes estatutos legales y la coexistencia de relaciones laborales mercantiles y coactivas. Dentro de los mismos establecimientos productivos se combinaban diferentes relaciones sociales de producción.

Ambos aspectos remiten a un tercero: la existencia de una antigua tradición de normas y prácticas coactivas que, lejos de desaparecer con la generalización del trabajo asalariado y la abolición legal de la esclavitud -entre 1842 y 1846 en Uruguay, y entre 1853 y 1860 en Argentina-, parecen haberse profundizado en diferentes ámbitos productivos durante la aceleración capitalista. Todo esto es relevante porque las formas de resistencia y de acción colectiva de los trabajadores fueron situadas y 
estuvieron en buena medida determinadas por las condiciones del mercado de trabajo, el grado de acceso a otras formas de subsistencia por fuera de este mercado y por la eficacia de los dispositivos de coacción.

En el largo período aquí considerado, las calificaciones de "vagos", "perjudiciales", "haraganes", "insolentes", "indóciles", "altaneros" y "revoltosos" fueron recurrentes en el discurso de patrones y autoridades para describir a los trabajadores y, especialmente, a los peones que se contrataban temporalmente. Esos tópicos refieren a los márgenes de autonomía, de movilidad espacial y ocupacional que esos trabajadores ostentaban y que porfiadamente intentaron defender y preservar. Una queja habitual era que los trabajadores "abandonaban" la relación laboral, algo que en muy pocas ocasiones pudo ser anulado a través de las estrategias de endeudamiento. Aunque muy pocas veces suministren indicios de que se tratara de acciones colectivamente organizadas, esa posibilidad no debiera ser descartada.

Impedir esas prácticas, no pocas veces calificadas también como "fuga" o "deserción", fue uno de los objetivos de un conjunto de normas coercitivas y en especial de la famosa "papeleta de conchabo", que entre mediados del siglo XVIII y principios del XIX comenzó a exigirse en toda la región considerada. Estas disposiciones explicitan la voluntad gubernamental disciplinadora pero también sugieren el reconocimiento de que las relaciones laborales funcionaban bajo una suerte de regulación social: por eso las referencias a los "salarios acostumbrados", montos salariales y modos de pago que estaban regulados por normas sociales de carácter local y que incluso podian ser consideradas válidas para algunas formas de conchabo compulsivo. Esto parece haber sustentado cierta capacidad negociadora de los peones, y no solo para reclamar los montos "acostumbrados" sino también para que los patrones respetasen algunas restricciones consagradas al ritmo de trabajo y a la extensión de la jornada laboral, el pago de un plus salarial por realizar tareas que no habian sido pactadas previamente o por trabajar en horarios y dias que las costumbres reconocian como no laborables, como las horas de siesta, las destinadas a la oración o los días de fiesta. Estas condiciones solían regular también la composición de las raciones que debian recibir los trabajadores y los momentos en que ellas debian ser suministradas. De esta manera, esas mismas disposiciones coactivas llevaban inscripta la existencia de prácticas sociales en las que eran claves las formas de negociación, que difícilmente hayan sido exclusivamente individuales. Obviamente, la capacidad negociadora podía acrecentarse en algunas épocas del año y la ejercían con mayores posibilidades de éxito los trabajadores calificados y/o aquellos que aportaban a la relación laboral sus propios medios de producción. Por caso, a fines de 1794 el Cabildo porteño se quejaba de que los peones que se contrataban con sus 
propias yeguas "exigen por la Trilla lo que se les antoja" (Acuerdos del Extinguido Cabildo de Buenos Aires, 1932: 445-453).

La inestabilidad de buena parte de los trabajadores libres en la región ha sido objeto de intensa discusión historiográfica, y no hace falta reponerla aquí. ${ }^{2}$ Sí cabe anotar que, junto a las disposiciones coercitivas que emanaban de las autoridades para forzar el conchabo de los trabajadores, los empleadores no solo apelaron a salarios y jornales más altos sino también a pagar una parte anticipadamente. Y fueron estos adelantos la causa de muchas denuncias judiciales contra trabajadores, así como de sucesivas e infructuosas prohibiciones para erradicarlos. Es en algunas de esas ocasiones cuando se pudo registrar que quienes habian "abandonado" a su empleador lo habian hecho en forma colectiva y simultánea. Por dar un solo ejemplo, en 1805 un abastecedor de carbón desde Gualeguay acusó a los peones que había conchabado de dejarlo; según sus palabras, "mas como sea propio de estas gentes, el pedir adelantado a los que se hallan necesitados de su trabajo, al tiempo de levantar los hornos, se me fueron todos, sin reparar que estaban debiendo" (Perri, 2015: 352). ${ }^{3}$

Se entiende entonces que también encontraran enormes dificultades para efectivizarse los intentos de encuadrar las relaciones laborales dentro de un marco formal más estricto e imponer la obligación del uso de la contrata laboral escrita. En Buenos Aires, al menos hasta después de mediados del siglo XIX, seguian siendo repetidas las quejas por la vigencia de los anticipos salariales y las contratas verbales (Benítez, 1864: 195). No eran las únicas dificultades que habian hallado aun los terratenientes más grandes, quienes vieron diluirse sus sucesivos ensayos con nuevas formas de trabajo coactivo, como ocurrió en la provincia en las décadas de 1830 y 1840, cuando, ante la demanda creciente de trabajadores para las estancias incrementada por el peso del reclutamiento militar, la erosión del trabajo esclavo y la interrupción ocasional de las migraciones temporales por motivos políticos, apelaron al trabajo de indígenas cautivos y después a la contratación de peones gallegos endeudados, intentos que fallaron porque no pudieron anular

2. Remitimos al debate ya clásico entre Carlos Mayo, Samuel Amaral, Juan Carlos Garavaglia y Jorge Gelman en el Anuario del IEHS número 2 (AA.VV., 1987) y a la discusión entre Jorge Gelman y Jonathan Brown-Ricardo Salvatore sobre la inestabilidad de la fuerza de trabajo en la Estancia de las Vacas, en la Banda Oriental (en Fradkin, 1993).

3. Las fugas también eran frecuentes entre los esclavos, y en Buenos Aires se siguieron practicando a mediados de siglo entre niños y jóvenes, muchas veces negros, que ingresaban como aprendices en talleres de artesanos urbanos, donde de hecho eran mano de obra gratuita o muy barata, con muy malas condiciones de vida y trabajo (Mitidieri, 2017: 53). 
la capacidad negociadora de los trabajadores (Gelman, 1999). Mayor parece haber sido la eficacia de estas iniciativas en el Estado Oriental, en donde a la utilización de indios cautivos se agregó la contratación de peones canarios y formas más o menos disimuladas de perduración de la esclavitud bajo la figura de los "colonos africanos", aún después de la abolición legal (Palermo, 2008; Thul, 2017; Borucki, 2017). ${ }^{4}$

Las dificultades de los patrones continuaron al menos hasta fines de la década de 1870, a pesar de que ese dispositivo normativo se hiciera mucho más eficaz y expeditivo (Garavaglia, 2001; Sedeillán, 2006-2007). En 1865 se sancionó en Buenos Aires el Código Rural, que buscó afianzar los derechos de propiedad, controlar los usos rurales basados en la costumbre y eliminar alternativas a emplearse para subsistir. Estas medidas tenían antecedentes, pero ahora el Estado contaba con más fuerza para hacerlas cumplir. ${ }^{5}$

En muy diferentes áreas rurales el período de aceleración de la expansión capitalista y de generalización del trabajo asalariado fue también aquel en que se reforzaron y perfeccionaron las disposiciones y prácticas coercitivas. En Uruguay, la ley de vagancia de 1882 declaró vagos a quienes no tuvieran bienes o rentas y que siendo aptos para el trabajo no ejercieran ninguna profesión, arte u oficio. Las penas variaban: los orientales eran remitidos al servicio de las armas y los extranjeros al destierro o la prisión (Armand Ugón, 1881: 362). En Entre Ríos también se dictó una nueva "Ley de Vagos" en la década de 1860, a través de la cual se intentó penalizar el "abandono" del trabajo exigiendo papeletas de antecedentes de conducta para circular y obtener empleo. A su vez, en 1878 fue sancionado el Código Rural en el cual se preveía que las contratas laborales fueran escritas y registradas en un libro que a tal efecto debía tener cada alcalde de distrito.

El examen de la aplicación de estas medidas ha permitido verificar que, a diferencia de lo que sucedía durante la primera mitad del siglo, las autoridades no solo detenían a menesterosos y a migrantes recién llegados sino también a los productores poseedores de ranchos, tropillas, rodeos y enseres de labranza. Resultaba claro que los grandes propietarios no podian recurrir ya a las "soluciones" a las que apelaban a principios del siglo, y con el correr de las décadas en la fuerza de trabajo rural dejó de haber esclavos, disminuyeron los labradores

4. De modo análogo, las "conquistas" de la Patagonia y del Chaco también crearon condiciones propicias para la utilización de indios cautivos como peones en los ingenios del Noroeste y del Nordeste.

5. Todavía en 1881 la municipalidad de Buenos Aires intentó nuevamente imponer el uso de una libreta de conchabo a los sirvientes, lo que generó la protesta de los mozos de hoteles y demás dependientes (Allemandi, 2015: 163-164) 
y aumentaron significativamente los peones y jornaleros asalariados. No se dispone de evidencias firmes acerca de lo sucedido en las estancias y saladeros, pero los dispositivos legales montados sugieren que el "abandono" del trabajo y el ausentismo siguieron siendo frecuentes, así como también parece claro que en ocasiones algunas demandas de campesinos y trabajadores tendieron a canalizarse a través de la oficialidad de las compañias de milicias en que estaban encuadrados (Djenderendjian, 2011; Schmit y Alabart, 2013). Sin embargo, en esos saladeros entrerrianos junto al río Uruguay emergieron también otras formas de acción colectiva: las huelgas.

\section{Las huelgas anteriores a 1878}

Algunos estudios han señalado que una huelga se produjo en 1854 en el saladero Gianello de Gualeguaychú. Los peones se negaban a aceptar las papeletas de pago y suspendieron sus tareas. Dos años después, un encargado informaba que era imperioso arreglar la situación pues "yo estoy sitiado por los peones, donde quiera que me halle, hace un rato que me han sacado de a bordo de un buque, donde me había refugiado". La causa le parecía fácil de detectar: "No pague Ud sus dependientes sirvientes y peones, y hallará Ud la clave del mismo misterio" (Schmit, 2008; Leyes, 2014). En los años siguientes los conflictos escalaron a través de enfrentamientos verbales y huelgas parciales hasta una huelga de todos los trabajadores de un establecimiento. En agosto de 1858, una "pandilla" de trabajadores vascos del gran saladero Santa Cándida -cuyo propietario era Justo José de Urquiza, y donde compartian labores con peones criollos, escoceses, irlandeses e ingleses- decidió "plantar el trabajo". El administrador anotó "que nunca fueron tan imprudentemente exigentes" (Schmit, 2008). En los años siguientes la tensión se planteó también en la grasería a la cual los trabajadores se negaban a regresar si no se les pagaba lo adeudado. De modo que en 1862 "todos ellos se han convenido unánimemente" y no solo la "pandilla" de vascos (Román, 2004).

En estos años de fuerte transformación de las relaciones de producción parece haberse operado, entonces, una convergencia de las tradiciones de lucha que portaban tanto los trabajadores nativos como los inmigrantes. Y aunque es probable que los conflictos expresaran demandas económicas, no por ello deben haber dejado de tener implicancias politicas, en la medida que erosionaban la consistencia de las jerarquías existentes. No por nada los encargados de los saladeros entrerrianos se referian a estas huelgas como "sublevaciones" o "levantamientos"; no hablaron de "huelgas".

El vocablo ya figuraba en los diccionarios españoles al menos desde 
1734. Para entonces era definido de dos modos sugestivamente diferentes: por un lado, como "cesación del trabajo"; por otro se afirmaba que "Vale también placer, regocijo y recreación, que ordinariamente se tiene en el campo o en algún sitio ameno" (Diccionario de la lengua castellana, 1734: 185-2). Para inicios del siglo XIX las definiciones se han modificado: la primera ha desaparecido y ahora se incluyen otras dos acepciones: "El espacio de tiempo que uno está sin trabajar" y "El tiempo que media sin labrarse la tierra" (Diccionario de la lengua castellana, 1803: 470-1). Fue recién en 1884 que se agregó otra definición: "Abandono del trabajo, con que los que se ocupan en un arte u oficio quieren obligar a que se les conceda lo que pretenden; como por ejemplo, aumento de salario o disminución de horas de labor" (Diccionario de la lengua castellana, 1884: 578-2).

Las experiencias en los saladeros entrerrianos invitan a indagar las que puedan haberse producido en otras zonas. Por lo que se sabe, en los saladeros de Montevideo trabajaban conjuntamente trabajadores calificados y no calificados, libres y esclavos, e imperaba un régimen de disciplina de tipo penitenciario. A pesar de ello, se registraron diversas formas de protesta y resistencia: una fueron las "fugas" de esclavos, a veces para trabajar con otro amo y otras para escapar más allá del Río Negro "para incorporarse a los anarquistas"; pero en ocasiones también se produjo la paralización del trabajo, tal como sucedió en 1837, abarcando a varios saladeros simultáneamente. No casualmente las autoridades consideraron algunos de estos episodios como un "motín de peones" (Thul, 2014: 133-141). Pero este tipo de medidas no era exclusivo de los saladeros. En enero de 1839, el alcalde ordinario de la ciudad de Colonia denunciaba que los ordenanzas y escribientes de los juzgados de paz se negaban "a desempeñar sus empleos" ya que se les adeudaban 17 meses de sueldo (AGN Uruguay, AGA, MinGob, caja 912, carpeta 1 ).

La práctica tenía antecedentes ya largos. En la recientemente fundada Montevideo de 1750 el atraso en el pago de los salarios redundaba en que quienes se ocupaban en la construcción "o no trabajan por mucho que se vele sobre ellos o lo que hacen es cosa de mala gana". En algunas ocasiones los trabajadores efectuaron peticiones colectivas, como hicieron maestros y oficiales de la construcción en 1761 amenazando con abandonar sus puestos de trabajo o, como decía el maestro mayor Francisco Meneses: "sin plata no trabaja y que si se le paga trabajará". Las resistencias al ritmo de trabajo y las fugas, a su vez, parecen haber sido muy fuertes entre los indios tapes y guaranies que estaban asignados a las obras y que al parecer en más de una ocasión intentaron amotinarse, como también sucedía entre los presidiarios que trabajaban alli (Luque Azcona, 2007: 279-291). En 1769, los peones voluntarios de 
las reales obras de Montevideo -muchos de ellos eran a la vez soldadospidieron un aumento de salarios y amenazaron con "no trabajar de hoy en más en dichas obras, si no se les aumentaba a su jornal de cuatro reales diarios un real más" (Rodríguez Molas, 1957: 52). Desde Buenos Aires, las autoridades se negaron y se desconoce cómo siguió el conflicto.

Sí se sabe que en 1792 una docena de carpinteros y catorce calafateros de la maestranza del puerto en Montevideo protestaron ante una rebaja en sus jornales dispuesta por sus superiores, violando lo que consideraban como una "costumbre casi inmemorial" (Bentancur, 1997: 215). Y que hubo ocasiones en las que los mismos asalariados forzaron un proceso de negociación: eso hicieron en 1775 los operarios empleados en las Reales Obras cuando acudieron "todos en común" ante el comandante del fuerte de Santa Teresa para expresar sus reclamos de que se les pagaran los jornales de los días en que las obras se paralizaban por lluvia o por la falta de carbón. De este modo, tal como sucedía en el medio rural, era frecuente que en la ciudad los trabajadores abandonaran su trabajo para emplearse en el sector privado, y que los conchabados y voluntarios se escaparan para contratarse en la siega, actitudes que no sorprenden pues se ha verificado que la demanda laboral para estas obras era muy estacional (Thul, 2016).

En Buenos Aires no tenemos registros de este tipo de huelgas hasta mucho más tarde (lo cual no quiere decir que no haya habido ninguna). ${ }^{6}$ Se afirmó que una tuvo lugar en 1855, cuando los coristas del Teatro Argentino reclamaron que se hiciera una función anual en su beneficio (Yunque, 1984: 139). En el convulsionado 1871, año de la gran epidemia de fiebre amarilla, un periódico señalaba que "los serenos se han sublevado y no quieren concurrir a sus puestos porque se les debe varios meses de sueldo. La ciudad está abandonada iQué escándalo!" (La Tribuna, 6 de julio de 1871). Nótese que se seguía hablando de sublevación para la no concurrencia al trabajo. Un grupo de serenos advirtió a otro diario que no iban a volver a trabajar hasta que les pagasen los tres meses que les adeudaban (La Prensa, 7 de julio de 1871).

Poco más tarde, unos 250 calafateros y marineros -catalanes, franceses, italianos y griegos-protagonizaron un conflicto salarial en la Boca del Riachuelo (La Prensa, 5 de octubre de 1871). El problema era que "varios agentes de lanchas de los que abastecen frutas del país desde Barracas hasta Balizas se habian puesto de acuerdo para bajar el sueldo de los marineros que trabajaban en esa carrera" (El Nacional, 5 de octubre de 1871). Por lo tanto, "una parte de los marineros de buques

6. Además, aparentemente se produjo una huelga en los astilleros de la ciudad de Corrientes en 1868, pero no hemos hallado información fidedigna sobre ella. En 1877 hubo una huelga de aguateros en Rosario. 
de cabotaje "reclutó" otro número de camaradas, entre los trabajadores del mar de aquel mismo punto, se puso en marcha, con igual intento al departamento de Barracas, munidos de banderas y entregados a gritos descompasados de ¡Mueran los monopolizadores del trabajo, los ladrones!" (La Tribuna, 5 de octubre de 1871). La policía dispersó sin violencia a los protagonistas de lo que fue llamado por los dos últimos diarios mencionados un "motín". Pero La Prensa introdujo un sinónimo: denominó al episodio "una huelga o motín contra los empresarios".

\section{Deserciones, motines y sublevaciones}

Las experiencias de los varones en el ejército y en las milicias no pueden ser soslayadas en esta aproximación pues sin ellas no es comprensible la historia de las clases populares durante el siglo XIX. Los trabajadores compusieron siempre el grueso de las tropas (soldados, cabos y sargentos). Sobre ellos recayó primordialmente el reclutamiento compulsivo y durante varias décadas esa leva se convirtió en el objeto principal de la persecución de la "vagancia". Los márgenes de autonomía de las poblaciones campesinas y sus posibilidades de reproducción se vieron muy restringidos bajo la presión reclutadora, de modo que ella creaba condiciones más propicias para empujar su proceso de proletarización (Garavaglia, 2003).

En las filas de los ejércitos los reclutas de diversos orígenes raciales, sociales, regionales y ocupacionales tuvieron experiencias compartidas, aun cuando la estructura tendía más a forjar identidades y solidaridades de cuerpo antes que clasistas. A su vez, las milicias reforzaban los lazos de pertenencia territorial y mantenían la segmentación racial en la configuración de las unidades. Pero la mayor parte del tiempo las tareas que desempeñaban reclutas y milicianos no eran muy diferentes de las que realizaban como peones de campo o artesanos. El servicio de armas amplió sustancialmente la esfera del trabajo asalariado y fue uno de los espacios de mayor concentración de trabajadores.

Pese a ello, la transformación de los paisanos en soldados obedientes se demostró extremadamente dificultosa y las evidencias sugieren que la experiencia en las armas los dotó de saberes que nutrieron su capacidad de protesta, acción colectiva e intervención politica. Algunas de las disputas desarrolladas en el ejército o las milicias presentan cierta analogía con las que se producian en el mundo del trabajo, como en el caso con el que inicia este artículo.

Tomemos un ejemplo: cuando se decidió conformar las primeras compañias de Blandengues de la Frontera de Buenos Aires en 1752, el Cabildo tuvo que negociar con los propios milicianos el pago por adelantado de varios meses de servicio para lograr que se alistaran (Fradkin, 
2014). Este tipo de soluciones -demostrativas de los límites que tenía la coerción-no resolvió los problemas y en los años siguientes el retraso en el pago del prest -como se llamaba al pago-generó intensas disputas: así, en 1762 los soldados se retiraron de la compañia de Salto y la situación solo fue momentáneamente contenida con pagos a cuenta; pero al año siguiente volvieron a reclamar y se presentaron ante su capitán amenazando con una deserción colectiva. Los soldados pusieron sus demandas por escrito y el capitán terminó autorizándolos a que fueran a efectuar la petición un cabo y los soldados que ellos mismos eligieran (Alemano, 2016: 266-268).

Estos episodios muestran que el servicio de milicias estaba sometido a negociaciones y constituía un campo de fuerzas en tensión. Como habria de repetirse en múltiples ocasiones posteriormente, los milicianos exigian adelantos de sus haberes, tal como solian hacer los peones con sus empleadores y, por tanto, que esa deuda se convirtiera en un dispositivo de sujeción dependía menos de la voluntad que de la relación de fuerzas. Muestran también que la autoridad de jefes y oficiales estaba lejos de ser omnimoda y que muchas veces debían contemplar las demandas de los milicianos -que no eran un conjunto de campesinos enteramente subordinados-y hasta convertirse en sus portavoces. Esta fue una de las formas más perdurables de la acción colectiva popular y uno de los mecanismos de construcción de liderazgos locales. No obstante, los episodios sugieren algo más: los milicianos podían convertir a la compañía en un espacio para articular solidaridades, desarrollar una acción colectiva que se apropiara del derecho de petición extremando sus alcances y eligiendo sus propios representantes.

De esta manera, el servicio de armas parece haberse convertido en un espacio en el cual se conformó una densa tradición de luchas por el salario y las condiciones de vida. Las deserciones fueron un fenómeno absolutamente generalizado y adquirieron enorme magnitud durante las guerras de la revolución, al punto que para 1816 las autoridades calculaban que una unidad militar que fuera movilizada desde Buenos Aires al frente norte perderia entre un tercio y la mitad de sus efectivos en la marcha (Rabinovich, 2013: 137). En ambas situaciones, el cobro del prest, la alimentación, el vestuario y los malos tratos fueron las causas más frecuentes de descontento; es decir, lo que estaba en disputa era el trabajo que realizaban los soldados, su remuneración y las condiciones del servicio (Fradkin, 2013). Un solo ejemplo de muchísimos posibles: un soldado contó que "la causa de haber desertado fue el verse sumamente pobre: que no le faltó el rancho ni vestuario, pero que dinero jamás le dieron a buena cuenta" (Di Meglio, 2006: 167). A su vez, entre los milicianos se agregaban otros motivos como el incumplimiento de los turnos de rotación, la negativa a ser movilizados a zonas alejadas, 
prestar el servicio bajo el mando de oficiales regulares o su pretensión de convertir en electivos a sus jefes e incluso a los mismos comandantes que debian gobernar los pueblos y los partidos rurales.

$Y$ en condiciones críticas, los descontentos podían dar lugar a motines o sublevaciones, que fueron muy numerosos a lo largo del siglo XIX. Hay muchísimos ejemplos, desde movimientos como el que organizaron en la Buenos Aires de 1815 unos sargentos de artillería "para salir a formarse a la Plaza con todos los cañones, a pedir que se nos pagase", ya que los sueldos estaban muy atrasados (Di Meglio, 2006: 176), hasta el protagonizado en la Montevideo de 1843 por 60 efectivos vascos, que desertaron haciendo fuego contra sus compañeros; hubo varias razones, entre las que estaba el atraso de sus sueldos (Etchechury, 2015).

La posibilidad de actuar colectivamente y con armas en la mano permitió en ocasiones defender derechos laborales. En 1822 un propietario quiso desalojar en San Pedro a lo que llamó un grupo de "vagos", pero que según un juez era "una multitud de milicianos" cuyos servicios en años previos habian sido premiados por el gobierno con esos terrenos, sin títulos y sin pagar un canon. Fueron dilatando el desalojo, siguieron reiterando las siembras, designaron a uno de los suyos como representante y propusieron pagar un arrendamiento, pero no aceptaron marcharse. Vecinos de la zona recomendaban no proceder a un desalojo violento, ante el cual "tememos montonera". Cuatro años más tarde el conflicto continuaba y el juez de paz declaraba que "no he procedido por la fuerza porque no la tengo y pudiera traer consecuencias funestas", dado que "hay más de 50 hombres con sus respectivas familias y todos armados, pues son soldados de la Milicia activa del Estado" (Fradkin, 2001).

Este repertorio de acción colectiva se mantuvo durante décadas y estaba aún vigente en las de 1860 y 1870 , cuando la organización militar y los dispositivos de control y disciplinamiento eran mucho más consistentes. Las fugas, deserciones y evasión del servicio seguían siendo habituales, mientras que también continuaba la tradición de pedidos colectivos de dispensa del servicio o incluso las sublevaciones.

Probablemente la mayor de esas sublevaciones fueron los famosos desbandes de las tropas entrerrianas que iban a marchar a la guerra contra Paraguay, producidos en Toledo y Basualdo en 1865. Como tantas veces habia sucedido antes, los informes que recibía Urquiza repetian que "se piensa Gritar en la Reunión que no marchan si no se les Paga" y lo cierto es que en Toledo la desbandada fue precipitada por suboficiales y tropa, y que la forma organizativa que sustentaba la revuelta era la misma estructura miliciana conformada para imponer obediencia y subordinación a los paisanos (Alabart, 2015; Fradkin, 2013). 


\section{Organizaciones y política}

Para completar este breve panorama de las acciones colectivas que en parte moldearon la experiencia de los trabajadores rioplatenses, es importante tener en cuenta otros aspectos, como los intentos organizativos. Los gremios de artesanos fueron poco exitosos en el Río de la Plata colonial. En la Buenos Aires de fines del siglo XVIII se quiso fundar un gremio de zapateros, pero algunos miembros, sobre todo europeos, impugnaron la elección de autoridades porque maestros "de segunda clase", pardos y morenos, habian participado en ese acto a pesar de tenerlo prohibido. Más tarde los zapateros pardos y morenos quisieron crear un gremio diferenciado, y fueron otra vez obstaculizados por el grupo rival. Desde España se autorizó la concreción de dos gremios separados, pero las autoridades locales decidieron terminar con el largo conflicto y no autorizaron a ninguno de los dos (Johnson, 2013). Las diferencias raciales jugaron un papel decisivo.

Los artesanados porteño y montevideano no tuvieron asociaciones estables en el siglo XIX, como sí ocurrió en otras ciudades americanas. Sin embargo, en varias ocasiones se expresaron colectivamente. Así ocurrió en Buenos Aires en 1836: días después de que el gobierno de Rosas sancionara una ley que ponía aranceles a varios productos, los zapateros le solicitaron que directamente se prohibiera importar calzado. Se reunieron y nombraron comisionados para redactar la petición, que fue firmada por 618 personas (Katz, 2017: 11).

Hay otros episodios de organización ante conflictos puntuales. En 1842, veinte aguateros de Montevideo se negaron a pagar el impuesto de dos reales por pipa de agua que pretendian cobrarles (AGN Uruguay, AGA, MinGob, caja 940, carpeta 8). Unos años antes, el "gremio de carretilleros" denunció la presencia de algunos "falsos carretilleros" que falsificaban documentación para cobrar viajes que nunca habian hecho (El Comercio del Plata, 30 de junio de 1836). En 1834 un grupo de grandes abastecedores de carne de Buenos Aires impulsó un nuevo reglamento para su actividad, intentando terminar con la autonomía de los peones de los mataderos, quienes tenían bastante control sobre el proceso de producción ya que se encargaban de tareas que iban desde matar a los animales a vender la carne y el cuero. Estos peones, que se autodenominaron "abastecedores", actuaron colectivamente para reivindicar su libertad de participar en el mercado, y discutieron punto por punto el reglamento propuesto (Salvatore, 2003). Donde el nuevo reglamento decía que "todo abastecedor deberá ser matriculado, y acreditar tener existencias, como son carretas, puestos de carne y demás útiles de matanza", los peones respondieron que "todo abastecedor deberá ser matriculado, podrá traer ganado y matar o vender a quien 
sea de su gusto por más que no tenga carretas ni puesto, como se ha acostumbrado siempre”. Esta lucha en nombre de lo que era consuetudinario frente a los avances de los derechos de propiedad, los contratos y las codificaciones fue un elemento persistente que llevó a la acción popular durante todo el siglo XIX. Con distintas periodizaciones -desde el período tardocolonial en partes de la Banda Oriental, la década de 1820 en Buenos Aires, después de la mitad de siglo en Entre Ríos- los habitantes rurales se movilizaron por esa causa, y también ocurrió en las ciudades.

Esto se relaciona con un último aspecto, que no hay espacio para desarrollar: la participación política. Como es sabido, ella subsumió en muchos momentos del siglo XIX tensiones raciales y sociales, incluidas laborales, que se expresaron a través de la conflictividad entre facciones y partidos. Por ejemplo, en la Buenos Aires de Rosas, ser su partidario o un opositor podía definir un diferendo no surgido de la política, fuera criminal, civil o laboral (Di Meglio, 2007). La identidad política permitió incluso que grupos que tenían mayores impedimentos para las acciones colectivas pudieran canalizar sus malestares, como ocurría con quienes trabajaban en el ámbito doméstico.

Los episodios que delineamos remiten a trabajadores varones, 1o cual no quiere decir que sea una cuestión histórica; es más probablemente un problema historiográfico, de enfoques. Aunque recientemente hubo aproximaciones importantes a distintos grupos de trabajadoras de Buenos Aires antes de 1880 (Allemandi, 2015; Schettini, 2016; Mitidieri, 2017), todavía falta mucho por investigar sobre sus luchas en los más variados ámbitos laborales. Por ejemplo, en San Luis (fuera del área aquí considerada), las maestras de la Escuela Graduada, debido a los "grandes descuentos del valor del pret que por nuestro trabajo nos asignan", advirtieron que "no nos queda otro remedio que suspender las tareas escolares" e iniciaron una huelga (Monitor de la Educación Común, $\mathrm{n}^{\circ}$ 2, 1881: 53-54).

\section{Conclusiones}

¿Cómo se relaciona lo expuesto con la clase obrera afianzada en el área rioplatense a fines del siglo XIX? Si desde la década de 1880 se hicieron frecuentes en Buenos Aires y Montevideo las huelgas en la industria textil y del calzado, los puertos, los mercados de frutos, los ferrocarriles y otros transportes, en la construcción, las panaderías y la fabricación de fideos, ¿'solo pueden explicarse en el tiempo corto, por los recientes cambios estructurales, por la formación de nuevas organizaciones de clase y la circulación de ideas de izquierda provenientes de Europa? Ninguno de estos factores debe ser soslayado. Pero nuestro 
interrogante es: ¿hasta qué punto pueden también haber tenido un lugar las experiencias de luchas forjadas desde el siglo XVIII?

Por ejemplo, ¿la conflictividad en los saladeros entrerrianos de mediados del siglo XIX nutrió la que años después se desarrolló entre los trabajadores de los frigoríficos? No lo sabemos, pero a fines de 1894 se produjo la que parece haber sido la primera huelga en uno de ellos, en Las Palmas, al norte de Zárate. Y fue a fines de esa década que aparecieron las primeras asociaciones de obreros de frigorificos (Tarditti, 2008: 63-64). La cuestión importa pues la ola huelguística de principios del siglo XX no se restringió solo a Buenos Aires y Montevideo, sino que abarcó a muchas ciudades (Andreassi Cieri, 1991; Boido, 2002; Poy, 2014).

$¿$ En qué medida las experiencias en el ejército y la milicia influyeron en la formación de los primeros movimientos de protesta obrera? ¿Hasta dónde la participación popular decimonónica dejó sus huellas no solo en los movimientos políticos del siglo XX sino también en los modos de acción en conflictos laborales? El estado de las investigaciones no permite todavia responder estos interrogantes y tan solo es posible tener en cuenta los indicios que hemos presentado.

Pero es claro es que para comprender lo que pasó después de 1880 es necesario visibilizar la permanencia de los miembros de la sociedad previa. Para ello es útil recuperar algunas de las conocidas observaciones de Bialet Massé, quien en 1904 registraba que las organizaciones obreras estaban integradas mayoritariamente por inmigrantes recientes, aunque advertía que durante las cosechas "es de ver a ese criollo ladino y socarrón hacer lo que le da la gana, y al primer reto pedir que le arreglen la cuenta para irse; y gracias si al pedirla uno no la piden todos" (Bialet Massé, 2010: 180). La movilidad espacial y ocupacional de los trabajadores y su "insolencia" continuaban siendo irresolubles para los patrones. Si esto podría ser visto como una actitud individual, no dejaba de tener implicancias colectivas. De todos modos, en diversas actividades se siguió apelando al reclutamiento de estos trabajadores para enfrentar las huelgas sindicalmente organizadas: "criollos del Interior" llevados a Rosario en 1902 frente a la huelga de estibadores, correntinos y entrerrianos convocados a Buenos Aires por la gran huelga de portuarios, y varios casos más (Bialet Massé, 2010: 188-200). Por lo tanto, si bien las patronales pueden haber obstruido la organización obrera y la eficacia de las huelgas, contribuyeron también a crear condiciones propicias para la integración de trabajadores de muy diferente origen, experiencias y tradiciones en una misma clase.

Y esto se torna más significativo si se lo examina a largo plazo: los movimientos migratorios provenientes del mundo campesino de las provincias del interior para trabajar temporal o definitivamente como 
asalariados en el bajo litoral y en Buenos Aires eran un fenómeno crucial al menos desde el siglo XVIII, que se explica no solo por los salarios más altos y más monetizados o por la menor rigidez de las relaciones coactivas sino también por las mayores oportunidades de empleo y de acceso a la tierra. Sin este condicionante estructural de la conformación del mercado de trabajo, que ni siquiera la gran inmigración producida desde la década de 1870 pudo anular, no se comprenden ni las vertientes que configuraron la clase trabajadora ni la eficacia de la "fuga" como estrategia de resistencia. Y aunque no tuvimos espacio para plantearlas, también en las provincias hubo largas experiencias de conflicto protagonizadas por los trabajadores.

Las fragmentarias evidencias relevadas suscitan más interrogantes que conclusiones taxativas. Su relevancia reside en que ayudan a precisar un problema que merece una investigación mucho más amplia y necesariamente colectiva. Cobran mayor entidad si se las sitúa en el contexto de las enormes dificultades que pudieron afrontar los trabajadores rioplatenses para desplegar acciones colectivas en sus ámbitos laborales. Sus posibilidades estuvieron limitadas no solo por factores coyunturales o circunstanciales sino también estructurales. Por lo pronto, porque muy pocos establecimientos productivos concentraban un grupo numeroso de trabajadores: es por ello que tiene particular importancia considerar sus experiencias de protesta y resistencia en las unidades militares o milicianas.

Hubo otros factores limitantes: la diversidad de orígenes regionales y raciales, los distintos estatutos legales en que estaban inscriptos, los disímiles niveles de calificación, la combinación de distintas relaciones de producción dentro de los mismos establecimientos, las posibilidades de encontrar otros modos de subsistencia por fuera del mercado de trabajo o las cambiantes relaciones con los dispositivos de poder. En ese contexto, las migraciones laborales hacian factibles la circulación y el intercambio de tradiciones de lucha, ideas y experiencias, pero también pudieron obstaculizar las posibilidades de acción colectiva y aumentar la diferenciación.

Debemos enfatizar algo más. La expansión del trabajo asalariado fue una tendencia decimonónica central, aunque es probable que hasta muy avanzado el siglo los salarios no conformasen el componente principal y permanente de los ingresos de las familias trabajadoras y, sobre todo, que no estuvieran en condiciones de asegurar la supervivencia y menos su reproducción. Con todo, la información disponible atestigua la capacidad de los trabajadores para disputar los niveles de remuneración $\mathrm{y}$, en algunas coyunturas, incluso un aumento de los salarios reales (Gelman y Santilli, 2015; Moraes y Thul, 2017).

La generalización del trabajo asalariado, entonces, no se desarrolló 
en forma simple ni lineal sino de manera contradictoria y con enormes variaciones tanto regionales como entre las distintas ramas de la actividad económica. La tendencia se desplegó en simultáneo a la erosión de la esclavitud, aunque coexistió con el desarrollo de otras formas de trabajo coactivo. Tampoco puede ser asimilada a un proceso de proletarización y menos a una expropiación generalizada de los medios de producción que disponían los trabajadores. Algunas evidencias del Buenos Aires rural, por ejemplo, indican que hasta mediados del siglo XIX el aumento del número de asalariados no significó la desaparición del amplio espectro de pequeños productores, que por el contrario persistieron e incluso aumentaron. Así, los hogares rurales de no propietarios seguían disponiendo de acceso a los medios de producción y ello parece haber incidido en el funcionamiento del mercado de trabajo y el nivel de los salarios. Y no es improbable que, también, lo haya hecho en sus estrategias y modos de acción.

Mirando hacia adelante aparece como necesario aumentar las exploraciones sobre el peso de las prácticas y vivencias de las mujeres, los criollos, indígenas y afrodescendientes, y los trabajadores forzados en el origen del movimiento obrero. Ello ayudará a complejizar la construcción de un sujeto colectivo que, a partir de su propia experiencia, se estaba constituyendo como clase.

\section{Referencias}

AA.VV. (1987), "Estudios sobre el mundo rural. Polémica: gauchos, campesinos y fuerza de trabajo en la campaña rioplatense colonial", Anuario IEHS, $\mathrm{n}^{\circ} 2$, pp. 25-70.

Alemano, María Eugenia (2016), El Imperio desde los márgenes. La frontera del Buenos Aires borbónico (1752-1806), Tesis de Doctorado, Universidad de San Andrés.

Allemandi, Cecilia (2015), Sirvientes, criados y nodrizas. Una aproximación a las condiciones de vida y trabajo en la ciudad de Buenos Aires a partir del servicio doméstico (fines del siglo XIX-principios del XX), Tesis de Doctorado en Historia, Universidad de San Andrés.

Alabart, Mónica (2015), "Los desbandes de Basualdo y Toledo: hacia la fractura del federalismo entrerriano", en Roberto Schmit (ed.), Caudillos, politica e instituciones en los orígenes de la Nación Argentina, Los Polvorines: Ediciones UNGS, pp. 101-131.

Andreassi Cieri, Alejandro (1991), "Inmigración y huelga. Argentina, 19001920", Ayer, no 4, pp. 117-145.

Armand Ugón, Enrique et al. (1881), Compilación de leyes y decretos, Tomo 13, Montevideo.

Benítez, Mariano (1864), Antecedentes y fundamentos del Proyecto de Código Rural, Buenos Aires: Imprenta de Buenos Aires. 
Bentancur, Arturo (1997), El puerto colonial de Montevideo, Montevideo: FHCE, vol. 1.

Bialet Massé, Juan (2010), Informe sobre el estado de las clases obreras argentinas, La Plata: Ministerio de Trabajo de la Provincia de Buenos Aires, vol. 2.

Boido, Jorge (2002), La primera huelga general en la República Argentina. Sus caracteristicas y significados como expresión de la presencia de los obreros como clase en la lucha político-económica, Tesis de Licenciatura, UNLu.

Borucki, Alex (2017), De compañeros de barco a camaradas de armas. Identidades negras en el Río de la Plata, 1760-1860, Buenos Aires: Prometeo.

Chalhoub, Sidney y Fernando Teixeira da Silva (2009), "Sujeitos no imaginário académico: escravos e trabalhadores na historiografia brasileira desde os anos 1980", Cad. AEL, vol. 14, n ${ }^{\circ}$ 26, pp. 15-45.

Di Meglio, Gabriel (2006), ;Viva el bajo pueblo! La plebe urbana de Buenos Aires y la politica entre la Revolución de Mayo y el rosismo, Buenos Aires: Prometeo.

- (2007), ¡Mueran los salvajes unitarios! La Mazorca y la politica en tiempos de Rosas, Buenos Aires: Sudamericana.

Djenderendjian, Julio (2011), "Optimizando recursos escasos en un área de frontera. La opción por la mano de obra esclava en las grandes estancias entrerrianas coloniales", Quinto Sol, vol.15, n 2, pp. 1-27.

Etchechury, Mario (2015), "De colonos y súbditos extranjeros a "ciudadanos en armas". Militarización y lealtades políticas de los españoles residentes en Montevideo, 1838-1845", Revista Universitaria de Historia Militar, vol. 4, pp. 119-142.

Falcón, Ricardo (1984), Los orígenes del movimiento obrero, 1857-1899, Buenos Aires: CEAL.

Fradkin, Raúl (comp.) (1993), La historia agraria del Río de la Plata colonial. Los establecimientos productivos, I, Buenos Aires: CEAL.

- (2001), “¿“Facinerosos" contra "cajetillas»? La conflictividad rural en Buenos Aires durante la década de 1820 y las montoneras federales", Illes i Imperis, $\mathrm{n}^{\circ} 4$, pp. 5-33.

- (2013), "La participación política popular en el litoral rioplatense durante el siglo XIX. Notas y conjeturas", en Gabriel Di Meglio y Raúl Fradkin (coords.), Hacer politica. La participación popular en el siglo XIX rioplatense, Buenos Aires: Prometeo, pp. 239-272.

- (2014), "Las milicias de caballería de Buenos Aires, 1752-1805", Fronteras de la Historia, vol. 19, $\mathrm{n}^{\circ} 1$, pp. 124-150.

Garavaglia, Juan Carlos (2001), "De Caseros a la guerra del Paraguay: el disciplinamiento de la población campesina en el Buenos Aires postrosista (1852-1865)", Illes $i$ Imperis, $\mathrm{n}^{\circ}$ 5, pp. 53-80.

- (2003), "Ejército y milicia: los campesinos bonaerenses y el peso de las exigencias militares, 1810-1860", en Anuario IEHS, 18, pp. 153-187.

Gelman, Jorge (1999), "El fracaso de los sistemas coactivos de trabajo rural 
en Buenos Aires bajo el rosismo. Algunas explicaciones preliminares", Revista de Indias, vol. LIX, $\mathrm{n}^{\circ}$ 215, pp. 123-141.

Gelman, Jorge y Daniel Santilli (2015), "Salarios y precios de los factores en Buenos Aires, 1770-1880. Una aproximación a la distribución funcional del ingreso en el largo plazo", Revista de Historia Económica, vol. 33, n 1, pp. $153-186$.

Grez Toso, Sergio (2007), De la "regeneración del pueblo" a la huelga general. Génesis y evolución histórica del movimiento popular en Chile (1810-1890), Santiago: RIL.

Iñigo Carrera, Nicolás (2011), "La clase obrera en Argentina, ayer y hoy", Travesia, $\mathrm{n}^{\circ} 13$.

Johnson, Lyman (2013), Los Talleres de la revolución. La Buenos Aires plebeya y el mundo del Atlántico, 1776-1810, Buenos Aires: Prometeo.

Katz, Mariana (2017), "Los artesanos proteccionistas. Buenos Aires, primera mitad del siglo XIX", Economía y Politica, vol. 4, n 2, pp. 5-36.

Leyes, Rodolfo (2014), "Destellos de un nuevo sujeto: Los conflictos obreros en los saladeros y la formación de la clase obrera entrerriana (18541868)", Mundo Agrario, vol. 15, $\mathrm{n}^{\circ} 30$.

Luque Azcona, Emilio (2007), Ciudad y poder: la construcción material y simbólica del Montevideo colonial (1723-1810), Sevilla: CSIC-Universidad de Sevilla-Diputación de Sevilla.

Mafud, Julio (1988), La clase obrera argentina, Buenos Aires: Distal.

Marotta, Sebastián (1960), El movimiento sindical argentino. Su génesis y desarrollo. Periodo 1857-1907, Buenos Aires: Lacio.

Mitidieri, Gabriela (2017), Costureras, modistas, sastres y aprendices. Una aproximación al circuito de trabajo de la costura. Buenos Aires, 1852-1862, Tesis de Licenciatura en Historia, UBA.

Moraes, María Inés y Florencia Thul (2017), "Los salarios reales y el nivel de vida en una economía latinoamericana colonial: Montevideo entre 1760-1810", Revista de Historia Económica, vol. 36, n 2, pp. 185-213.

Palermo, Eduardo (2008), "Cautivos en las estancias de la frontera uruguayo-brasileña”, Mundo Agrario, vol. 9, n 17.

Perri, Gladys (2015), El trabajo y los trabajadores en el mundo rural durante una época de transición. Buenos Aires, 1780-1830, Tesis de Doctorado, Universidad Pablo de Olavide.

Poy, Lucas (2014), Los origenes de la clase obrera argentina: huelgas, sociedades de resistencia y militancia politica en Buenos Aires, 1888-1896, Buenos Aires: Imago Mundi.

Rabinovich, Alejandro (2013), Ser soldado en las Guerras de Independencia. La experiencia cotidiana de la tropa en el Río de la Plata, 1810-1824, Buenos Aires: Sudamericana.

Ratzer, José (1969), Los marxistas argentinos del 90, Córdoba: Pasado y Presente.

Rodríguez Molas, Ricardo (1957), "Una huelga en el Montevideo de 1769", Boletín Histórico, Montevideo: Estado Mayor del Ejército, $\mathrm{n}^{\circ}$ 71-72. 
Román, César (2004), "Los cambios en la protesta: los trabajadores de las estancias y saladeros. El caso del oriente entrerriano (1850-1862)", PIMSA. Documentos y Comunicaciones, $\mathrm{n}^{\circ}$ 46, pp. 54-71.

Salvatore, Ricardo (2003), Wandering Paysanos. State Order and Subaltern Experience in Buenos Aires during the Rosas Era, Durham: Duke University Press.

Schettini, Cristiana (2016), "Ordenanzas municipales, autoridad policial y trabajo femenino: la prostitución clandestina en Buenos Aires, 18701880", Revista Historia y Justicia, n 6, Santiago de Chile, pp. 72-102.

Schmit, Roberto (2008), "Poder político y actores subalternos en Entre Ríos, 1862-1872", Anuario IEHS, no 23, 199-226.

Schmit, Roberto y Mónica Alabart (2013), "Cambio institucional y prácticas sociales en los orígenes del capitalismo rioplatense: Entre Ríos, 18601878", Quinto Sol, vol. 17, n 1, pp. 1-24.

Sedeillán, Gisela (2006-2007), "Las leyes sobre la vagancia: control policial y práctica judicial en el ocaso de la frontera (Tandil 1872-1881)", Trabajos y Comunicaciones, $\mathrm{n}^{\circ}$ 32-33, pp. 141-166.

Sowell, David (2006), Artesanos y politica en Bogotá, 1832-1919, Bogotá: Pensamiento Crítico - Círculo de Literatura Alternativa.

Tarcus, Horacio (2007), Marx en la Argentina. Sus primeros lectores obreros, intelectuales y científicos, Buenos Aires: Siglo XXI.

Tarditti, Roberto (2008), La formación de la clase obrera. Alcances y limites de la organización sindical de los obreros de frigorifico durante la presidencia de Yrigoyen. Las huelgas de 1917-1918 en Avellaneda, Tesis de Doctorado, FFyL, UBA, t. I.

Thul, Florencia (2014), Coerción y relaciones de trabajo en el Montevideo independiente, 1829-1842, Tesis de Maestría, Facultad de Humanidades y Ciencias de la Educación, Udelar.

- (2016), "Entre la coacción y la resistencia. Prácticas asociativas de los trabajadores de Montevideo en la década de 1830", en A Contracorriente, vol. $14, \mathrm{n}^{\circ} 1$, pp. 148-172.

- (2017), "Deuda, trabajo y coerción. Las experiencias de colonización canaria en el Estado Oriental del Uruguay (1830-1843)", Anuario de Estudios Americanos, vol. 74, $\mathrm{n}^{\circ} 1$, pp. 185-209.

Viñas, David (1971), De los montoneros a los anarquistas, Buenos Aires: Carlos Pérez.

Yunque, Álvaro (1984), Leandro Alem. El hombre de la multitud, tomo 1, Buenos Aires: CEAL.

Zubillaga, Carlos y Jorge Balbis (1985), Historia del movimiento sindical uruguayo, tomo I: Cronología y fuentes (hasta 1905), Montevideo: Banda Oriental. 